\title{
Proteolysis of Myosin during Platelet Storage
}

\author{
Joel Abramowitz, Alfred Stracher, and Thomas C. Detwiler \\ From the Department of Biochemistry, State University of New York Downstate \\ Medical Center, Brooklyn, New York 11203
}

\begin{abstract}
A B S T R A C T Physical properties of actomyosin from either fresh or stored platelets have been compared. Actomyosin obtained from platelets after 3 days of storage contained myosin that was $60-80 \%$ degraded to myosin rod. No myosin rod was detected in fresh platelets. The platelet myosin rod is similar to the rod produced by limited proteolysis of skeletal muscle myosin.
\end{abstract}

\section{INTRODUCTION}

About $15 \%$ of the total platelet protein consists of contractile proteins that are similar to the actomyosin complex isolated from skeletal muscle $(1,2)$. Adelstein, Pollard, and Kuehl (3) reported that the platelet actomyosin complex contained, in addition to actin and myosin, large amounts of two myosin fragments; a globular "head" portion ( $m o l ~ w t=100,000$ ) and a rod-shaped "tail" portion ( $\mathrm{mol} \mathrm{wt}=130,000$ ). In the course of our research on platelet contractile proteins, such fragments had never been observed, and we thought it possibly significant that Adelstein et al. worked with stored platelets, while we had always used platelets isolated from fresh blood. We have now compared actomyosins from fresh and stored platelets and have consistently found that only stored platelets have myosin fragments.

\section{METHODS}

Fresh platelets were isolated immediately after collection of blood, and stored platelets were obtained from a blood bank as platelet concentrates that had been stored for 3 days at either $4^{\circ} \mathrm{C}$ or $22^{\circ} \mathrm{C}$ (no differences between these temperatures were observed). The platelets were washed three times in isotonic $\mathrm{NaCl}$ with $6 \mathrm{mM}$ EDTA. Actomyosin was prepared essentially as described by Bettex-Galland and Luscher (1), except that the three precipitations were car-

Received for publication 30 November 1973 and in revised form 31 January 1974.

The Journal of Clinical Investigation Volume 53 May 1974·1493-1496 ried out at an ionic strength of 0.07 and a $\mathrm{pH}$ of 6.5 . The methods for sucrose gradient centrifugation and sodium dodecyl sulfate (SDS)-gel electrophoresis have been described (4). Electron microscopy was performed under conditions described by Adelstein et al.

\section{RESULTS}

Platelet myosin is assumed to be similar to skeletal muscle myosin, which is composed of two identical subunits coiled to form a long helical tail with a globular head. Fig. 1 illustrates the effect of limited proteolysis of skeletal muscle myosin leading to formation of myosin rod and myosin head, each with characteristic properties listed in the figure. The fragments of platelet myosin observed by Adelstein et al. were similar to the two fragments of skeletal muscle myosin in Fig. 1, except that the platelet myosin head was slightly smaller $(100,000$ mol wt), and the rod was slightly larger $(130,000 \mathrm{~mol}$ wt). We have studied the myosin rod as a measure of degradation of the myosin molecule, because it is easily

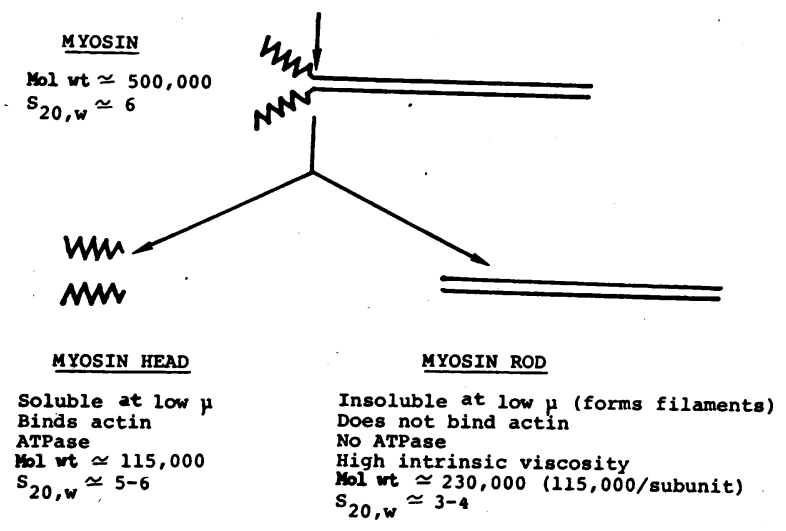

FIGURE 1 Properties of myosin fragments. Data from references 5 and 6 . 


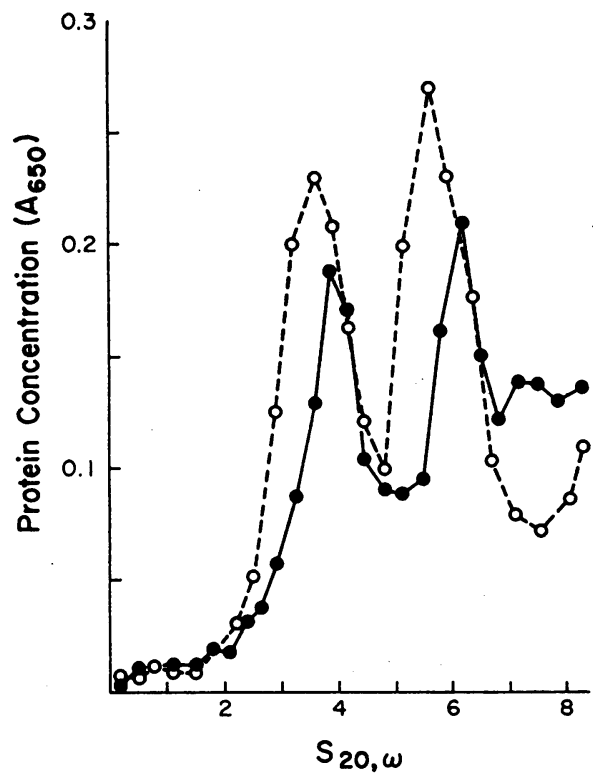

FIGURE 2 Centrifugation of actomyosin from fresh $(\mathrm{O}-\mathrm{O})$ or stored (sucrose gradients containing $10 \mathrm{mM}$ CaATP. Experimental details have been described (4).

isolated from platelet actomyosin by sucrose gradient centrifugation, and its properties (described in Fig. 1) make identification conclusive.

When actomyosin from fresh platelets was centrifuged on a sucrose gradient containing $10 \mathrm{mM}$ CaATP and $0.5 \mathrm{M} \mathrm{KCl}$, the characteristic pattern (Fig. 2, dotted line) was found. As previously described (4), the three components of platelet actomyosin are separated by this procedure: a pellet of polymerized actin, a $5.8 \mathrm{~S}$ peak of myosin, and a $3.6 \mathrm{~S}$ peak of an actin-like protein. Centrifugation of actomyosin from stored platelets resulted in a similar pattern (Fig. 2, solid line). However, SDSgel electrophoresis of the protein from these gradients revealed two distinct differences between actomyosin from fresh and from stored platelets. The 3.6S peak from fresh platelets (Fig. $3 a$ ) showed a single protein of $45,000 \mathrm{~mol} \mathrm{wt}$, the actin-like protein. In contrast, half of the protein in the same peak from stored platelets (Fig. $3 b$ ) had a mol wt of 130,000 . Furthermore, a comparison of the material found in the myosin peaks (Fig. $3 c$ and $3 d$ ) showed that there is much less intact myosin and more $80,000-130,000$-mol wt protein in actomyosin from stored platelets.

To establish that the 130,000 -mol wt protein found in the 3.8S peak from stored platelets only was indeed the myosin rod, analogous to the $115,000-\mathrm{mol}$ wt rod of skeletal muscle myosin (Fig. 1), it was isolated by centrifuging actomyosin from stored platelets on a sucrose gradient containing $0.5 \mathrm{M} \mathrm{KCl}$ and $10 \mathrm{mM}$ imida- zole, $\mathrm{pH} 7.5 ; 11-14 \%$ of the total protein was recovered as a peak of about 3.8S. On SDS-gel electrophoresis, $85 \%$ of this material appeared as a single band with a mol wt of 130,000 (Fig. $3 e$ ). The following properties of this protein indicate that it is the myosin rod (see Fig. 1). (a) It must have the same solubility properties as actomyosin because it follows actomyosin through three precipitation cycles. $(b)$ It is not attached to
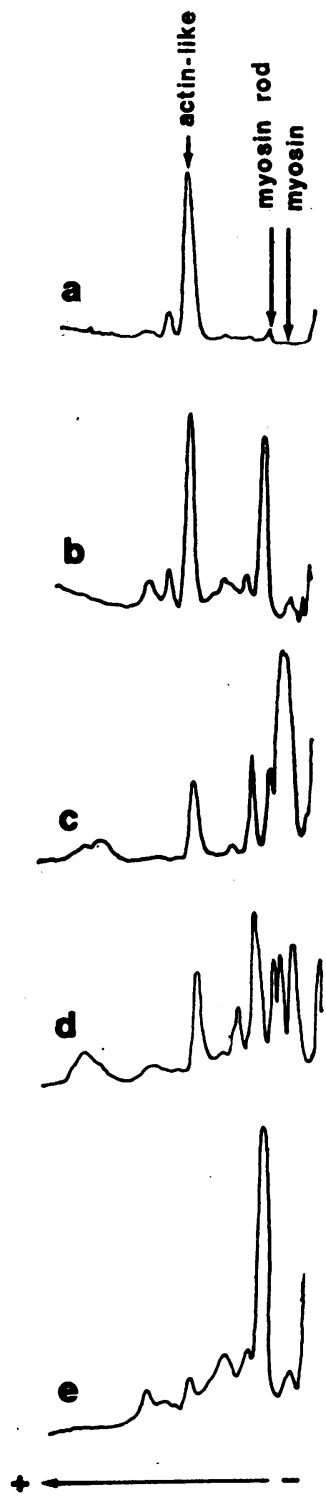

FIGURE 3 Densitometer tracings of SDS-gel electrophoresis of proteins from the sucrose gradients of Fig. 1 and of purified myosin rod. Experimental details have been described (4). (a) $3.6 \mathrm{~S}$ peak from fresh platelets, $(9 \mu \mathrm{g})$; (b) $3.8 \mathrm{~S}$ peak from stored platelets $(18 \mu \mathrm{g}) ;(c) 5.8 \mathrm{~S}$ peak from fresh platelets $(22 \mu \mathrm{g}) ;(d) 6.1 \mathrm{~S}$ peak from stored platelets (28 $\mu \mathrm{g})$; (e) purified myosin rod $(15 \mu \mathrm{g})$. 


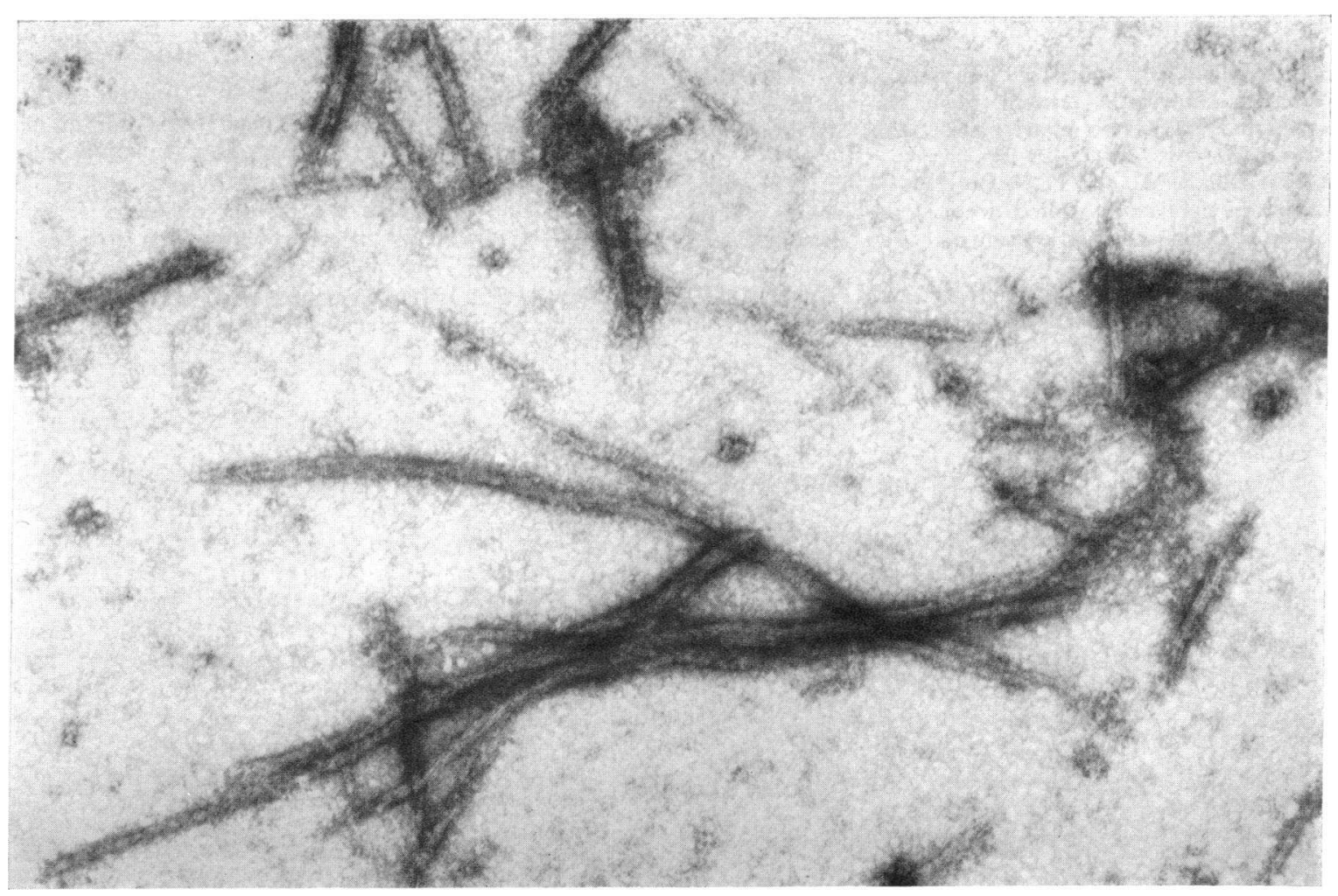

FIGURE 4 Negatively stained myosin rod filaments prepared as described by Adelstein et al (3). $\times 71,955$.

actomyosin as demonstrated by its isolation by sucrose gradient centrifugation. $(c)$ The high molecular weight and low sedimentation rate suggest a highly asymmetric protein. This was confirmed by measurement of the viscosity of a dilute solution $(0.4 \mathrm{mg} / \mathrm{ml})$, which indicated a reduced viscosity much greater than that for a globular protein. (d) It forms long filaments (Fig. 4) similar to those shown by Adelstein et al. and shorter filaments without typical myosin heads. Thus, the 130,000-mol wt protain is the myosin rod, a proteolytic fragment of myosin.

\section{DISCUSSION}

The presence of myosin rod and the decrease in amount of intact myosin in actomyosin from stored platelets clearly demonstrates partial degradation of myosin during platelet storage. The absence of myosin rod in fresh platelets, presumably a population composed of platelets of all ages, suggests that there is negligible degradation of platelet myosin during in vivo aging.

An estimate of the amount of myosin which has been degraded can be made on the basis of the total amount of myosin present in platelet actomyosin $(33 \%$ on a weight basis), the amount of myosin rod (11-14\% on a weight basis), and the contribution of the myosin rod to the total weight of the myosin molecule (about 50\%). We calculate that $60-80 \%$ of the platelet's myosin has been partially degraded after 3 days of storage. This must have a profound effect on platelet contractility and on any function it serves, but perhaps equally important, it raises the possibility that other proteins may also be subject to proteolysis. It is thus imperative to investigate the extent of proteolysis during platelet storage and to determine whether this proteolysis is the cause or effect of cell death. If, indeed, proteolysis contributes to cell death, inhibitors of proteolytic enzymes may prolong platelet viability during storage. Since the myosin rod can be readily isolated and identified, it should prove to be a useful indicator for such studies.

\section{ACKNOWLEDGMENTS}

We are grateful to Dr. Lawrence Herman, Department of Pathology, State University of New York Downstate Medical Center, for the electron micrographs. Stored platelets were obtained from the blood banks of the Maimonides Medical Center and the State University Hospital, Brooklyn, N. Y., and Jacobi Hospital, Bronx, N. Y.

This research was supported by grants HL10099 and HL14020 from the U. S. Public Health Service. 


\section{REFERENCES}

1. Bettex-Galland, M., and E. F. Lüscher. 1961. Thrombosthenin-a contractile protein from thrombocytes. Its extraction from human blood platelets and its properties. Biochim. Biophys. Acta. 49: 536.

2. Bettex-Galland, M., and E. F. Lüscher. 1965. Thrombosthenin, the contractile protein from blood platelets and its relation to other contractile proteins. Adv. Protein Chem. 20: 1 .

3. Adelstein, R. S., T. D. Pollard, and W. M. Kuehl. 1971. Isolation and characterization of myosin and two myosin fragments from human blood platelets. Proc. Natl. Acad. Sci. U.S. A. 68: 2703.

4. Abramowitz, J., A. Stracher, and T. Detwiler. 1972. The differential effect of Ca-ATP and Mg-ATP on platelet actomyosin. Biochem. Biophys. Res. Commun. 49: 958.

5. Lowey, S., H. S. Slayter, A. G. Weeds, and H. Baker. 1969. Substructure of the myosin molecule. I. Subfragments of myosin by enzymic degradation. J. Mol. Biol. 42: 1 .

6. Dreizen, P. 1971. Structure and function of the myofibrillar contractile proteins. Annu. Rev. Med. 22: 365 . 